Bull. Chem. Soc. Ethiop. 2019, 33(2), 307-319.

ISSN 1011-3924

(C) 2019 Chemical Society of Ethiopia and The Authors

Printed in Ethiopia

DOI: https://dx.doi.org/10.4314/bcse.v33i2.11

\title{
SYNTHESIS AND BIOLOGICAL EVALUATION OF SULFONAMIDE-BASED 1,3,4-OXADIAZOLE DERIVATIVES
}

\author{
Selvaraj Kavitha ${ }^{1 *}$, Zulfareen Nasarullah ${ }^{2}$ and Kulanthai Kannan ${ }^{1}$ \\ ${ }^{1}$ Department of Chemistry, Government College of Engineering, Salem-11, Tamilnadu, India \\ ${ }^{2}$ Department of Chemistry, Mahendra Engineering College, Namakkal-637503, Tamilnadu, \\ India
}

(Received June 6, 2017; Revised April 3, 2019; Accepted May 22, 2019)

\begin{abstract}
A novel series of 1,3,4-oxadiazole containing sulfonamide derivatives were synthesized by 5-(5cyclohexyl-1,3,4-oxadiazol-2-yl)-2-methyl-benzenesulfonyl chloride. A good yield of intermediate with various substituted like aryl/hetero was formed. All the synthesized compounds were characterized by FT-IR, ${ }^{1} \mathrm{H}$ NMR,

${ }^{13} \mathrm{C}$ NMR and mass spectral studies. These compounds were evaluated for their preliminary bioassay in vitro antimicrobial activity, anti-inflammatory and anti-diabetic activities. In this series, most of the compounds have good anti-inflammatory activity. Particularly, compounds 5c, 5d and 5e showed excellent anti-inflammatory activity with $\mathrm{IC}_{50}$ values of 110,110 , and $111 \mu \mathrm{g} / \mathrm{mL}$ than diclofenac $(157 \mu \mathrm{g} / \mathrm{mL})$. The frontier orbital energy and the global reactivity descriptor were discussed for the tested compounds using RB3LYP/311G(d,p) basis set. Results revealed that the theoretical calculations of antimicrobial activity were closely related to quantum chemical parameters.
\end{abstract}

KEY WORDS: 1,3,4-Oxadiazole, Sulfonamide, Antimicrobial, Anti-diabetic, Anti-inflammatory, FT, SAR

\section{INTRODUCTION}

Sulfonamides are one of the important drugs in medicinal chemistry, which are effective chemotherapeutic agents against microbial infection in human beings [1]. They are bacteriostatic in nature and block the biosynthesis of coenzyme (folate) resulting in the arrest of bacterial growth and cell division. Sulfonamide derivatives has been well known for their antitumor [2], anti-diabetic [3], anti-malarial [4], antimicrobial [5-6], anti-inflammatory [7], antioxidant [8], COX inhibitors [9], lipoxygenase inhibitors [10], alzheimer s disease [11], etc. Many literature survey revealed that 1,3,4-oxadiazole possess diverse pharmacological activities such as anticancer [12-14], antimicrobial [15-18], anti-HIV [19], antiproliferative [20], antiviral [21], anti-inflammatory [22-23], anticonvulsant [24]. Some of 2,5-disubstituted 1,3,4oxadiazole based entities have emerged as most potent antimicrobial activities.

Nowadays, many microorganisms are resistant to antibiotics. Therefore, it is essential to find a new and better multi drug. Similarly, bio nanomedicines are considered as one of the most promising technique. It is successfully implicated as a drug delivery system in the treatment of various diseases like antimicrobial [25-27], anticancer [28-29], anti-inflammatory [30], antivirus [31], etc.

In this paper, we have synthesized new 1,3,4-oxadiazole derivatives with sulfonamide and tested for in vitro antimicrobial, antidiabetic, and anti-inflammatory activities. Some principal quantum descriptors have been correlated with the antimicrobial activity of the synthesized compounds.

\section{EXPERIMENTAL}

General

The reagents and chemicals used in the study were available commercially. All the reactions were monitored by silica coated TLC plates. Solvents (ethyl acetate:petroleum ether) were used

*Corresponding author. kavisundar06@gmail.com

This work is licensed under the Creative Commons Attribution 4.0 International License 
as mobile phase. Melting points are uncorrected and checked by an electro thermal apparatus. FT-IR spectrums of synthesized compounds were recorded in the range of $4000-400 \mathrm{~cm}^{-1}$ using a Perkin-Elmer RX I spectrometer with $\mathrm{KBr}$ pellet. Bruker 300 and $400 \mathrm{MHz}$ NMR spectrometers (AVANCE II) were used to record $\mathrm{H}^{1} \mathrm{NMR},{ }^{13} \mathrm{C} \mathrm{NMR}$ spectra and $\mathrm{CDCl}_{3}$ is used as a solvent. The molecular mass of the compounds was confirmed by using thermo lcq Deca XP MAX spectrometer. Elemental analyses were also performed to calculate the amount of C, $\mathrm{H}$, and $\mathrm{N}$ using Perkin-Elmer 2400 analyzer.

\section{Synthesis of 2-cyclohexyl-5-p-tolyl-1,3,4-oxadiazole}

Toulic hydrazide $(1 \mathrm{mmol})$ and cyclohexanoic acid $(1 \mathrm{mmol})$ in phosphorous oxychloride $(7$ vol) were refluxed for $2-3 \mathrm{~h}$ at $110{ }^{\circ} \mathrm{C}$. The reaction progress was monitored on thin layer chromatography by using petroleum ether and ethyl acetate (7:3) as mobile phase and it was visualized in UV light. After completion of the reaction, the residue was allowed at room temperature and slowly poured into crushed ice with constant stirring. The solid was filtered off, washed with water repeatedly and dried, that afforded white solid as product. Yield $80 \%$. m.p. $92{ }^{\circ} \mathrm{C}$. FT-IR (KBr) in $\mathrm{cm}^{-1}$ : 1494, 1442 and 1411 (for oxadiazole), $1593(\mathrm{C}=\mathrm{N}), 1016(\mathrm{C}-\mathrm{O}-\mathrm{C})$, 2932, $2856\left(\mathrm{CH}_{2} \mathrm{Str}\right) .{ }^{1} \mathrm{H}$ NMR $\left(\mathrm{CDCl}_{3} 300 \mathrm{MHz}\right) \delta \mathrm{ppm}: 1.26-1.49(\mathrm{~m}, 3 \mathrm{H}), 1.61-1.79(\mathrm{~m}, 3 \mathrm{H})$, 1.85-1.93 (m, 2H), 2.13-2.19 (m, 2H), 2.45(s, 3H), 2.91-3.03 (m, 1H), $7.33(\mathrm{~d}, 2 \mathrm{H}, J=7.8 \mathrm{~Hz})$, $7.91(\mathrm{~d}, 2 \mathrm{H}, J=8.1 \mathrm{~Hz}) .{ }^{13} \mathrm{C} \mathrm{NMR}\left(\mathrm{CDCl}_{3}, 300 \mathrm{MHz}\right) \delta \mathrm{ppm}: 168.5,163.2,140.8,128.9,125.8$, $128.2,120.4,41.8,39.2,38.5,34.2$, and 29.2. LC/ESI: $\mathrm{m} / \mathrm{z}$ value $243(\mathrm{M}+1)$. Anal. calc. for $\mathrm{C}_{15} \mathrm{H}_{18} \mathrm{~N}_{2} \mathrm{O}$ (242): C, 74.4; H, 7.43; N, 11.56; O, 6.60. Found: C, 74.3; H, 7.32; N, 9.58; O, 6.62.

Synthesis of 5-(5-cyclohexyl-1,3,4 oxadiazol-2-yl)-2-methyl-benzenesulfonyl chloride

Chlorosulphonic acid (5 vol) was added to 2-cyclohexyl-5-p-tolyl-1, 3,4-oxadiazole (1 mmol) at $0{ }^{\circ} \mathrm{C}$. Then, the mixture was refluxed at $110{ }^{\circ} \mathrm{C}$ for $3 \mathrm{~h}$. The progress of the reaction was checked by TLC by petroleum ether and ethyl acetate $(8: 2)$ as mobile phase and was visualized in UV light chamber. The product was cooled at room temperature and poured into crushed ice slowly. The mixture was extracted with ethyl acetate, water, brine water and dried with anhydrous $\mathrm{Na}_{2} \mathrm{SO}_{4}$. The organic layer was concentrated under reduced pressure and finally the product was washed with petroleum ether to got afforded dirty white solid. Yield $68 \%$; m.p. $112{ }^{\circ} \mathrm{C}$. FT-IR $(\mathrm{KBr})$ in $\mathrm{cm}^{-1}$ : 2932, $2856\left(\mathrm{CH}_{2} \mathrm{Str}\right), 1485(\mathrm{C}=\mathrm{C}), 1593(\mathrm{C}=\mathrm{N}), 1335\left(\mathrm{SO}_{2}\right.$ str assym $), 1160\left(\mathrm{SO}_{2}\right.$ str sym), 1018 (C-O-C). ${ }^{1} \mathrm{H}$ NMR $\left(\mathrm{CDCl}_{3} 300 \mathrm{MHz}\right) \delta \mathrm{ppm}: 1.36-1.56(\mathrm{~m}, 4 \mathrm{H}), 1.64-1.71(\mathrm{~m}$, $4 \mathrm{H}), 2.13-2.18(\mathrm{~d}, 2 \mathrm{H}), 2.92(\mathrm{~s}, 3 \mathrm{H}), 2.93-3.07(\mathrm{~m}, 1 \mathrm{H}), 7.59(\mathrm{~d}, 1 \mathrm{H}, J=8.1 \mathrm{~Hz}), 8.33(\mathrm{dd}, 1 \mathrm{H}$, $J=7.8 \mathrm{~Hz}), 8.75(\mathrm{~s}, 1 \mathrm{H}) .{ }^{13} \mathrm{CNMR}\left(\mathrm{CDCl}_{3} 300 \mathrm{MHz}\right) \delta \mathrm{ppm}: 170.6,163.0,140.1,133.6,127.8$, 122.6, 118.8, 108.2, 35.3, 31.9, 29.7, 25.3, and 20.6. LC/ESI: $\mathrm{m} / \mathrm{z}$ value $341(\mathrm{M}+1)$. Anal calc. for $\mathrm{C}_{15} \mathrm{H}_{17} \mathrm{ClN}_{2} \mathrm{O}_{3} \mathrm{~S}(340)$ : C, 52.86; H, 5.03; N, 8.22; O, 14.08. Found: $\mathrm{C}, 52.76 ; \mathrm{H}, 5.02 ; \mathrm{N}$, 8.24; $\mathrm{O}, 14.12$.

\section{Synthesis of 1,3,4-oxadiazole-sulfonamide derivatives}

The suitable amine ( 1 equiv), pyridine (4 equiv) were dissolved in dichloro methane and 1,3,4oxdiazole-sulfonyl chloride derivative ( 1.2 equiv) was added in drop wise at $-2{ }^{\circ} \mathrm{C}$ to $-7{ }^{\circ} \mathrm{C}$. The organic reaction mixture was stirred at the room temperature for 2-4 h. After completion of the reaction, the reaction mixture was poured into ice water and was diluted with ethyl acetate, and washed with water, $2 \mathrm{M}$ hydrochloric acid, $10 \%$ sodium bicarbonate, brine water and dried with sodium sulfate. It was concentrated under reduced pressure to afforded sulfonamide as product [32]. 
5-(5-Cyclohexyl-[1,3,4] oxadiazol-2-yl)-N-(3-fluoro-phenyl)-2-methyl-benzenesulfonamide (5a). Yield 61\%; m.p. $187^{\circ} \mathrm{C}$. FTIR $(\mathrm{KBr})$ in $\mathrm{cm}^{-1}: 3120(\mathrm{NH}), 2935,2859\left(\mathrm{CH}_{2} \mathrm{str}\right), 1606(\mathrm{C}=\mathrm{N})$, $1488(\mathrm{C}=\mathrm{C}), 1336\left(\mathrm{SO}_{2}\right.$ str assym), 1167 ( $\mathrm{SO}_{2}$ str sym), 1070 (C-O-C), C-F (1270). ${ }^{1} \mathrm{H}$ NMR $\left(\mathrm{CDCl}_{3}, 300 \mathrm{MHz}\right) \delta: 1.30-1.45(\mathrm{~m}, 5 \mathrm{H}), 1.66-1.79(\mathrm{~m}, 2 \mathrm{H}), 1.87-1.91(\mathrm{~m}, 2 \mathrm{H}), 2.13-2.16(\mathrm{~d}$, 2H), $2.71(\mathrm{~s}, 3 \mathrm{H}), 6.63-6.73(\mathrm{~m}, 2 \mathrm{H}), 6.95(\mathrm{~s}, 1 \mathrm{H}), 7.10-7.17(\mathrm{~m}, 2 \mathrm{H}), 7.44(\mathrm{~d}, 1 \mathrm{H}, J=8.1 \mathrm{~Hz})$,

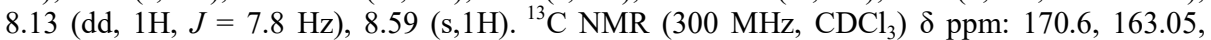
161.4, 140.9, 138.6, 133.6, 130.7, 127.8, 122.6, 116.1, 111.8, 107.9, 35.3, 31.9, 29.7, 25.3, 20.6. LC/ESI-MS: $\mathrm{m} / \mathrm{z}$ value; $416(\mathrm{M}+1)$. Anal calc. for $\mathrm{C}_{21} \mathrm{H}_{22} \mathrm{FN}_{3} \mathrm{O}_{3} \mathrm{~S}(415): \mathrm{C}, 60.71 ; \mathrm{H}, 5.34 ; \mathrm{N}$, 10.11 ; O, 11.55. Found: C, 60.51; H, 5.26; N, 9.57; O, 11.38.

5-(5-Cyclohexyl-[1,3,4]-oxadiazol-2-yl)-2-methyl-N-p-tolyl-benzenesulfonamide (5b). Yield $65 \%$; m.p. $119^{\circ}$ C. FTIR (KBr) in $\mathrm{cm}^{-1}: 3122(\mathrm{NH}), 2931,2856\left(\mathrm{CH}_{2} \mathrm{str}\right), 1577(\mathrm{C}=\mathrm{N}), 1512$ $(\mathrm{C}=\mathrm{C}), 1333\left(\mathrm{SO}_{2}\right.$ str assym $), 1158\left(\mathrm{SO}_{2}\right.$ str sym $), 1018(\mathrm{C}-\mathrm{O}-\mathrm{C}) .{ }^{1} \mathrm{H} \mathrm{NMR}\left(\mathrm{CDCl}_{3}, 300 \mathrm{MHz}\right)$ : $1.20-1.51(\mathrm{~m}, 1 \mathrm{H}), 1.60-1.78(\mathrm{~m}, 2 \mathrm{H}), 1.85-1.9(\mathrm{~m}, 2 \mathrm{H}), 2.10-2.15(\mathrm{~m}, 2 \mathrm{H}), 2.21(\mathrm{~s}, 3 \mathrm{H}), 2.69$ $(\mathrm{s}, 3 \mathrm{H}), 2.94-3.02(\mathrm{~m}, 1 \mathrm{H}), 7.01-7.06(\mathrm{~m}, 1 \mathrm{H}), 7.40(\mathrm{t}, 1 \mathrm{H}, J=8.1 \mathrm{~Hz}), 8.14(\mathrm{~d}, 1 \mathrm{H}, J=8.0 \mathrm{~Hz})$, $8.54(\mathrm{~s}, 1 \mathrm{H}), 9.82(\mathrm{~s}, 1 \mathrm{H}) .{ }^{13} \mathrm{C}$ NMR $\left(100 \mathrm{MHz}, \mathrm{CDCl}_{3}\right) \delta \mathrm{ppm}: 170.3,163.5,160.1,141.1,138.6$, 136.8, 133.1, 130.7, 129.8, 122.7, 122.3, 112.8, 110.9, 105.9, 35.3, 30.1, 25.7, 25.3 21.3, 20.7. LC/ESI-MS: m/z value; $412(\mathrm{M}+1)$. Anal calc. for $\mathrm{C}_{22} \mathrm{H}_{25} \mathrm{~N}_{3} \mathrm{O}_{3} \mathrm{~S}(411): \mathrm{C}, 64.21 ; \mathrm{H}, 6.12 ; \mathrm{N}$, 10.21; O, 11.66. Found: C, 64.01; H, 5.96; N, 9.87; O, 11.33.

5-(5-Cyclohexyl-[1,3,4]oxadiazol-2-yl)-N-(3-methoxy-phenyl)-2-methyl-benzenesulfonamide (5c). Yield 58\%; m.p. $126{ }^{\circ} \mathrm{C}$. FTIR (KBr) in $\mathrm{cm}^{-1}: 3128(\mathrm{NH}), 2936,2850\left(\mathrm{CH}_{2} \mathrm{str}\right), 1569$ $(\mathrm{C}=\mathrm{N}), 1522(\mathrm{C}=\mathrm{C}), 1337\left(\mathrm{SO}_{2}\right.$ str assym $), 1160\left(\mathrm{SO}_{2}\right.$ str sym $), 1040(\mathrm{C}-\mathrm{O}-\mathrm{C}) .{ }^{1} \mathrm{H}$ NMR $\left(\mathrm{CDCl}_{3}\right.$, $300 \mathrm{MHz}): 1.27-1.39(\mathrm{~m}, 4 \mathrm{H}), 1.66-1.79(\mathrm{~m}, 2 \mathrm{H}), 1.87-1.91(\mathrm{~m}, 2 \mathrm{H}), 2.13-2.16(\mathrm{~d}, 2 \mathrm{H}), 2.71(\mathrm{~s}$, $3 \mathrm{H}), 2.96-3.04(\mathrm{~m}, 1 \mathrm{H}), 3.73(\mathrm{~s}, 3 \mathrm{H}), 6.63-6.73(\mathrm{~m}, 2 \mathrm{H}), 6.95(\mathrm{~s}, 1 \mathrm{H}), 7.10-7.17(\mathrm{~m}, 2 \mathrm{H}), 7.44$ $(\mathrm{d}, 1 \mathrm{H}, J=8.1 \mathrm{~Hz}), 8.13(\mathrm{dd}, 1 \mathrm{H}, J=7.8 \mathrm{~Hz}), 8.59(\mathrm{~s}, 1 \mathrm{H}) .{ }^{13} \mathrm{C}$ NMR $\left(300 \mathrm{MHz}, \mathrm{CDCl}_{3}\right) \delta$ ppm: 170.5, 163.0, 160.3, 140.9, 138.7, 137.2, 133.5, 130.8, 130.2, 122.9, 122.5, 112.9, 110.9, 106.9, 55.3, 35.3, 30.1, 25.3, 20.8, 20.6. LC/ESI-MS: $\mathrm{m} / \mathrm{z}$ value; $428(\mathrm{M}+1)$. Anal calc. for $\mathrm{C}_{22} \mathrm{H}_{25} \mathrm{~N}_{3} \mathrm{O}_{4} \mathrm{~S}(427)$ : C, 61.81; H, 5.81; N, 9.83; O, 14.97. Found C: 61.62; H, 5.76; N, 9.77; O, 14.39.

$N$-(4-Chloro-phenyl)-5-(5-cyclohexyl-[1,3,4]oxadiazol-2-yl)-2-methyl-benzenesulfonamide (5d). Yield 63\%; m.p. $161{ }^{\circ} \mathrm{C}$. FTIR (KBr) in $\mathrm{cm}^{-1}: 3141(\mathrm{NH}), 2956,2862\left(\mathrm{CH}_{2} \mathrm{str}\right), 1568$ $(\mathrm{C}=\mathrm{N}), 1478(\mathrm{C}=\mathrm{C}), 1332\left(\mathrm{SO}_{2}\right.$ str assym $), 1165\left(\mathrm{SO}_{2}\right.$ str sym $), 1025(\mathrm{C}-\mathrm{O}-\mathrm{C}), 745(\mathrm{C}-\mathrm{Cl}) .{ }^{1} \mathrm{H}$ NMR $\left(\mathrm{CDCl}_{3}, 300 \mathrm{MHz}\right)$ : 1.19-1.31 (m, 1H ), 1.38-1.50 (m, 3H), 1.61-1.78 (m, 2H), 1.86-1.91 $(\mathrm{m}, 2 \mathrm{H}), 2.11-2.16(\mathrm{~m}, 2 \mathrm{H}), 2.73(\mathrm{~s}, 3 \mathrm{H}), 2.95-3.02(\mathrm{~m}, 1 \mathrm{H}), 6.99-7.02(\mathrm{~m}, 1 \mathrm{H}), 7.16-7.22(\mathrm{~m}$, $2 \mathrm{H}), 7.30(\mathrm{~d}, 1 \mathrm{H}, J=1.5 \mathrm{~Hz}), 7.43(\mathrm{~d}, 1 \mathrm{H} . J=7.8 \mathrm{~Hz}), 7.55(\mathrm{dd}, 1 \mathrm{H}, J=8 \mathrm{~Hz}), 8.14(\mathrm{dd}, 1 \mathrm{H}, J$ $=8.1 \mathrm{~Hz}), 8.63(\mathrm{~s}, 1 \mathrm{H}) .{ }^{13} \mathrm{C} \mathrm{NMR}\left(100 \mathrm{MHz}, \mathrm{CDCl}_{3}\right) \delta \mathrm{ppm}: 170.4,163.1,140.9,138.9,135.6$, 133.4, 130.7, 129.8, 128.9, 128.1, 127.2, 122.1, 35.3, 30.1, 29.3, 25.4, 20.6. LC/ESI-MS: m/z value; 433(M+1). Anal calc. for $\mathrm{C}_{21} \mathrm{H}_{22} \mathrm{ClN}_{3} \mathrm{O}_{3} \mathrm{~S}$ (427): C, 58.39; H 5.13, N 9.73, O 11.11 . Found C 58.32, H 5.16, N 9.78, O 11.21.

$\mathrm{N}$-(4-Bromo-phenyl)-5-(5-cyclohexyl-[1,3,4]oxadiazol-2-yl)-2-methyl-benzene sulfonamide (5e). Yield 72\%; m.p. $156{ }^{\circ} \mathrm{C}$. FTIR (KBr) in $\mathrm{cm}^{-1}$ : $3106(\mathrm{NH}), 2927,2854\left(\mathrm{CH}_{2} \mathrm{str}\right), 1575(\mathrm{C}=\mathrm{N})$, $1484(\mathrm{C}=\mathrm{C}), 1336\left(\mathrm{SO}_{2}\right.$ str assym), $1159\left(\mathrm{SO}_{2}\right.$ str sym), 1069 (C-O-C), 590 (C-Br). ${ }^{1} \mathrm{H}$ NMR $\left(\mathrm{CDCl}_{3}, 300 \mathrm{MHz}\right): 1.31-1.49(\mathrm{~m}, 3 \mathrm{H}), 1.61-1.79(\mathrm{~m}, 3 \mathrm{H}), 1.86-1.91(\mathrm{~m}, 2 \mathrm{H}), 2.11-2.16(\mathrm{~m}$, $2 \mathrm{H}), 2.68(\mathrm{~s}, 3 \mathrm{H}), 2.95-3.03(\mathrm{~m}, 1 \mathrm{H}), 6.99-7.05(\mathrm{~m}, 2 \mathrm{H}), 7.33-7.37(\mathrm{~m}, 2 \mathrm{H}), 7.49(\mathrm{~d}, 1 \mathrm{H}, J=8.1$ $\mathrm{Hz}), 7.54(\mathrm{~s}, 1 \mathrm{H}), 8.11(\mathrm{dd}, 1 \mathrm{H}, J=8.1 \mathrm{~Hz}) .{ }^{13} \mathrm{C} \mathrm{NMR}\left(300 \mathrm{MHz}, \mathrm{CDCl}_{3}\right) \delta \mathrm{ppm}: 170.5,163.0$, 141.7, 140.9, 138.7, 135.4, 133.5, 132.4, 130.8, 127.8, 122.6, 118.5, 35.3, 30.1, 25.3, 20.6, 15.2. LC/ESI-MS: m/z value; $477(\mathrm{M}+1)$. Anal calc. for $\mathrm{C}_{21} \mathrm{H}_{22} \mathrm{BrN}_{3} \mathrm{O}_{3} \mathrm{~S}$ (476): C 52.95, H 4.65, N 8.82, O 10.08. Found C 51.83, H 4.60, N 8.85, O 10.12. 
5-(5-Cyclohexyl-[1,3,4]oxadiazol-2-yl)-2-methyl-N-(3-nitro-phenyl)-benzenesulfonamide (5f). Yield 56\%; m.p. $118{ }^{\circ} \mathrm{C}$. FTIR (KBr) in $\mathrm{cm}^{-1}: 3120(\mathrm{NH}), 2929,2855\left(\mathrm{CH}_{2} \mathrm{str}\right), 1617(\mathrm{C}=\mathrm{N})$, $1481(\mathrm{C}=\mathrm{C}), 1360\left(\mathrm{SO}_{2}\right.$ str assym $), 1160\left(\mathrm{SO}_{2}\right.$ str sym $), 1090(\mathrm{C}-\mathrm{O}-\mathrm{C}), 1530\left(\mathrm{C}-\mathrm{NO}_{2}\right) .{ }^{1} \mathrm{H}$ NMR $\left(\mathrm{CDCl}_{3}, 300 \mathrm{MHz}\right): 1.34-1.46(\mathrm{~m}, 4 \mathrm{H}), 1.68-1.77(\mathrm{~m}, 2 \mathrm{H}), 1.87-1.90(\mathrm{~m}, 2 \mathrm{H}), 2.12-2.15(\mathrm{~d}, 2 \mathrm{H})$, $2.74(\mathrm{~s}, 3 \mathrm{H}), 2.97-3.02(\mathrm{~m}, 1 \mathrm{H}), 7.34-7.43(\mathrm{~m}, 2 \mathrm{H}), 7.52(\mathrm{~d}, 1 \mathrm{H}, J=6.0 \mathrm{~Hz}), 7.84(\mathrm{~d}, 1 \mathrm{H}, J=$ $6.3 \mathrm{~Hz}), 8.03(\mathrm{~s}, 1 \mathrm{H}), 8.12(\mathrm{~d}, 1 \mathrm{H}, J=6.0 \mathrm{~Hz}), 8.63(\mathrm{~s}, 1 \mathrm{H}), 9.93(\mathrm{~s}, 1 \mathrm{H}) .{ }^{13} \mathrm{C}$ NMR $(300 \mathrm{MHz}$, $\left.\mathrm{CDCl}_{3}\right) \delta$ ppm: $169.6,163.4,141.5,140.6,138.7,130.9,130.1,127.8,122.3,118.6,36.2,30.6$, 25.1, 20.5, 14.3. LC/ESI-MS: $\mathrm{m} / \mathrm{z}$ value; $443(\mathrm{M}+1)$. Anal calc. for $\mathrm{C}_{21} \mathrm{H}_{22} \mathrm{~N}_{4} \mathrm{O}_{5} \mathrm{~S}(442): \mathrm{C} 57, \mathrm{H}$ 5.01, N 12.66, O 10.08. Found C 57.2, H 5.72, N 9.79, O 14.35.

5-(5-Cyclohexyl-[1,3,4]oxadiazol-2-yl)-N-(3,5-difluoro-phenyl)-2-methyl-benzene sulfonamide (5g). Yield 71\%; m.p. $198{ }^{\circ} \mathrm{C}$. FTIR (KBr) in $\mathrm{cm}^{-1}: 3094(\mathrm{NH}), 2934,2859\left(\mathrm{CH}_{2}\right.$ str), 1618 $(\mathrm{C}=\mathrm{N}), 1479(\mathrm{C}=\mathrm{C}), 1339\left(\mathrm{SO}_{2}\right.$ str assym $), 1172\left(\mathrm{SO}_{2}\right.$ str sym $), 1024(\mathrm{C}-\mathrm{O}-\mathrm{C}), 997(\mathrm{C}-\mathrm{F}) .{ }^{1} \mathrm{H}$ NMR $\left(\mathrm{CDCl}_{3}, 300 \mathrm{MHz}\right)$ : 1.30-1.51 (m, 4H), 1.61-1.78 (d, 2H), 1.86-1.90 (m, 2H), 2.12-2.17 $(\mathrm{dd}, 2 \mathrm{H}), 2.95-3.03(\mathrm{~m}, 1 \mathrm{H}), 2.71(\mathrm{~s}, 3 \mathrm{H}), 6.48-6.55(\mathrm{~m}, 1 \mathrm{H}), 6.71-6.77(\mathrm{~m}, 3 \mathrm{H}), 7.45(\mathrm{~d}, 1 \mathrm{H}, J$ $=8.1 \mathrm{~Hz}), 8.13(\mathrm{dd}, 1 \mathrm{H}, J=7.95 \mathrm{~Hz}) .{ }^{13} \mathrm{C}$ NMR $\left(300 \mathrm{MHz}, \mathrm{CDCl}_{3}\right) \delta \mathrm{ppm:} 170.4,164.5,161.9$, 138.5, 137.9, 128.7, 125.7, 124.1, 122.8, 118.7, 107.2, 35.2, 30.1, 25.7, 25.3, 14.6.LC/ESI-MS: $\mathrm{m} / \mathrm{z}$ value; $434(\mathrm{M}+1)$. Anal calc. for $\mathrm{C}_{21} \mathrm{H}_{21} \mathrm{~F}_{2} \mathrm{~N}_{3} \mathrm{O}_{3} \mathrm{~S}$ (433): C 58.19, H 4.88, N 9.69, O 11.07. Found C 58.32, H 4.78, N 9.72, O 11.13.

5-(5-cyclohexyl-[1,3,4]oxadiazol-2-yl)-2-methyl-N-naphthalen-2-yl-benzenesulfonamide (5h). Yield 69\%; m.p. $172{ }^{\circ} \mathrm{C}$. FTIR (KBr) in $\mathrm{cm}^{-1}$ : $3053(\mathrm{NH}), 2945,2856\left(\mathrm{CH}_{2}\right.$ str), $1584(\mathrm{C}=\mathrm{N})$, $1549(\mathrm{C}=\mathrm{C}), 1337\left(\mathrm{SO}_{2}\right.$ str assym), $1161\left(\mathrm{SO}_{2}\right.$ str sym), 1088 (C-O-C), ${ }^{1} \mathrm{H}$ NMR $\left(\mathrm{CDCl}_{3}, 300\right.$ MHz) $\delta$ ppm: 1.37-1.47 (m, 3H), 1.69-1.76 (m, 2H), 1.83-1.88 (m, 2H), 2.04-2.11 (m, 2H), 2.63 $(\mathrm{s}, 3 \mathrm{H}), 2.88-2.94(\mathrm{~m}, 1 \mathrm{H}), 7.03(\mathrm{~s}, 1 \mathrm{H}), 7.25(\mathrm{~d}, 1 \mathrm{H}, J=6.6 \mathrm{~Hz}), 7.32(\mathrm{t}, 1 \mathrm{H}, J=7.8 \mathrm{~Hz}), 7.40$ $(\mathrm{d}, 1 \mathrm{H}, J=8.1 \mathrm{~Hz}), 7.46-7.53(\mathrm{~m}, 2 \mathrm{H}), 7.73(\mathrm{~d}, 1 \mathrm{H}, J=8.4 \mathrm{~Hz}), 7.80-7.85(\mathrm{~m}, 1 \mathrm{H}), 7.93-7.97$ $(\mathrm{m}, 1 \mathrm{H}), 8.14(\mathrm{~d}, 1 \mathrm{H}, J=7.8 \mathrm{~Hz}), 8.49(\mathrm{~s}, 1 \mathrm{H}) .{ }^{13} \mathrm{C} \mathrm{NMR}\left(300 \mathrm{MHz}, \mathrm{CDCl}_{3}\right) \delta \mathrm{ppm}: 170.4$, $163.0,140.9,139.1,134.3,133.4,131.0,130.9,130.8,129.2,128.9,127.8,126.9,126.5,125.4$, 123.1, 122.7, 121.5, 35.2, 30.1, 25.3, 20.9, 14.2. LC/ESI-MS: $\mathrm{m} / \mathrm{z}$ value; $448(\mathrm{M}+1)$. Anal calc. for $\mathrm{C}_{25} \mathrm{H}_{25} \mathrm{~N}_{3} \mathrm{O}_{3} \mathrm{~S}$ (447): C 67.09, H 5.63, N 9.39, O 10.72. Found $\mathrm{C} 67.12, \mathrm{H} \mathrm{5.71,} \mathrm{N} \mathrm{9.43,} \mathrm{O}$ 10.83 .

5-(5-cyclohexyl-[1,3,4]oxadiazol-2-yl)-2-methyl-N-pyridin-2-yl-benzene sulphonamide (5i). Yield 65\%; m.p. $156{ }^{\circ} \mathrm{C}$. FTIR $(\mathrm{KBr})$ in $\mathrm{cm}^{-1}: 3053(\mathrm{NH}), 2923,2853\left(\mathrm{CH}_{2} \mathrm{str}\right), 1598(\mathrm{C}=\mathrm{N})$, $1552(\mathrm{C}=\mathrm{C}), 1334\left(\mathrm{SO}_{2}\right.$ str assym $), 1162\left(\mathrm{SO}_{2}\right.$ str sym $), 1035(\mathrm{C}-\mathrm{O}-\mathrm{C}),{ }^{1} \mathrm{H}$ NMR $\left(\mathrm{CDCl}_{3}, 300\right.$ MHz) $\delta$ ppm: 1.36-1.52 (m, 4H), 1.64-1.79 (m, 2H), 1.88-1.92 (m, 2H), 2.13-2.18 (d, 2H), 2.69 $(\mathrm{s}, 3 \mathrm{H}), 2.96-3.06(\mathrm{~m}, 1 \mathrm{H}), 6.77-6.82(\mathrm{~m}, 1 \mathrm{H}), 7.35(\mathrm{~d}, 1 \mathrm{H}, J=9 \mathrm{~Hz}), 7.40(\mathrm{~d}, 1 \mathrm{H}, J=8.1 \mathrm{~Hz})$, 7.66-7.72 (m, 1H), 8.09 (d, $1 \mathrm{H}, J=7.8 \mathrm{~Hz}), 8.31(\mathrm{dd}, 1 \mathrm{H}, J=6 \mathrm{~Hz}), 8.78(\mathrm{~s}, 1 \mathrm{H}), 13.9(\mathrm{~s}, 1 \mathrm{H})$. ${ }^{13} \mathrm{C}$ NMR $\left(100 \mathrm{MHz}, \mathrm{CDCl}_{3}\right) \delta \mathrm{ppm}: 170.4,163.4,155.7,143.3,141.2,140.7,138.7,133.3$, 130, 127.1, 122.3, 115.8, 113.3, 35.3, 30.2, 25.4, 20.7, 15.3. LC/ESI-MS: $\mathrm{m} / \mathrm{z}$ value; $399(\mathrm{M}+1)$. Anal calc. for $\mathrm{C}_{20} \mathrm{H}_{22} \mathrm{~N}_{4} \mathrm{O}_{3} \mathrm{~S}$ (398): C 60.28, H 5.56, N 14.06, O 12.05. Found C 60.42, H 5.57, N $14.09, \mathrm{O} 12.10$.

1-[5-(5-Cyclohexyl-[1,3,4]oxadiazol-2-yl)-2-methyl-benzenesulfonyl]-2,3-dihydro-1H-indole (5j). Yield 59\%; m.p. $98{ }^{\circ} \mathrm{C}$. FTIR (KBr) in $\mathrm{cm}^{-1}$ : 2932, $2853\left(\mathrm{CH}_{2} \mathrm{str}\right), 1600(\mathrm{C}=\mathrm{N}), 1473$ $(\mathrm{C}=\mathrm{C}), 1327\left(\mathrm{SO}_{2}\right.$ str assym $), 1160\left(\mathrm{SO}_{2}\right.$ str sym $), 1028(\mathrm{C}-\mathrm{O}-\mathrm{C}) .{ }^{1} \mathrm{H}$ NMR $\left(\mathrm{CDCl}_{3}, 300 \mathrm{MHz}\right) \delta$ ppm: 1.36-1.52 (m, 4H), 1.62-1.71 (m, 4H), 2.13-2.18 (d, 2H), $2.65(\mathrm{~s}, 3 \mathrm{H}), 2.93-3.10(\mathrm{~m}, 1 \mathrm{H})$, 3.12-3.15 (m, 2H), 4.02-4.10 (m, 2H), $6.98(\mathrm{t}, 2 \mathrm{H}, J=7.2 \mathrm{~Hz}), 7.07-7.18(\mathrm{~m}, 1 \mathrm{H}), 7.41(\mathrm{~d}, 1 \mathrm{H}, J$ $=8.0 \mathrm{~Hz}), 7.46(\mathrm{~d}, 1 \mathrm{H}, J=7.6 \mathrm{~Hz}), 8.11(\mathrm{~d}, 1 \mathrm{H}, J=8 \mathrm{~Hz}), 8.49(\mathrm{~s}, 1 \mathrm{H}) .{ }^{13} \mathrm{C}$ NMR $(300 \mathrm{MHz}$, $\left.\mathrm{CDCl}_{3}\right) \delta \mathrm{ppm}: 170.2,162.8,141.9,138.5,133.7,131.1,130.5,128.9,127.6,127.0,125.3$, $123.7,122.5,114.4,49.8,39.8,35.1,30.0,27.8,25.2,20.7$. LC/ESI-MS: $\mathrm{m} / \mathrm{z}$ value; $424(\mathrm{M}+1)$. 
Anal calc. for $\mathrm{C}_{23} \mathrm{H}_{25} \mathrm{~N}_{3} \mathrm{O}_{3} \mathrm{~S}$ (423): C 65.23, H 5.95, N 9.92, O 11.33. Found C 65.32, H 5.96, N 9.94, O 11.39.

1-[5-(5-Cyclohexyl-[1,3,4] oxadiazol-2-yl)-2-methyl-benzenesulfonyl]-6-nitro-2,3-dihydro-1Hindole (5k). Yield 56\%; m.p. $120{ }^{\circ} \mathrm{C}$. FTIR (KBr) in $\mathrm{cm}^{-1}: 2934,2855\left(\mathrm{CH}_{2} \mathrm{str}\right), 1597(\mathrm{C}=\mathrm{N})$, $1477(\mathrm{C}=\mathrm{C}), 1344\left(\mathrm{SO}_{2}\right.$ str assym), $1167\left(\mathrm{SO}_{2}\right.$ str sym $), 1077(\mathrm{C}-\mathrm{O}-\mathrm{C}), 1522\left(\mathrm{C}-\mathrm{NO}_{2}\right) .{ }^{1} \mathrm{H}$ NMR $\left(\mathrm{CDCl}_{3}, 300 \mathrm{MHz}\right) \delta \mathrm{ppm}: 1.36-1.48(\mathrm{~m}, 2 \mathrm{H}), 1.61-1.74(\mathrm{~m}, 2 \mathrm{H}), 1.86-1.89(\mathrm{~m}, 2 \mathrm{H}), 2.10-2.14$ $(\mathrm{d}, 2 \mathrm{H}), 2.67(\mathrm{~s}, 3 \mathrm{H}), 2.96-3.02(\mathrm{~m}, 1 \mathrm{H}), 7.26-7.30(\mathrm{~m}, 1 \mathrm{H}), 7.46-7.49(\mathrm{~m}, 1 \mathrm{H}), 7.89(\mathrm{~d}, 1 \mathrm{H}, J=$ $6.8 \mathrm{~Hz}), 8.14(\mathrm{~d}, 1 \mathrm{H}, J=7.6 \mathrm{~Hz}), 8.27(\mathrm{t}, 1 \mathrm{H}, J=7.6 \mathrm{~Hz}), 8.50(\mathrm{~s}, 1 \mathrm{H}) .{ }^{13} \mathrm{C}$ NMR $(300 \mathrm{MHz}$, $\left.\mathrm{CDCl}_{3}\right) \delta \mathrm{ppm}: 170.5,162.9,141.7,138.2,133.8,131.1,130.4,128.2,127.1,127.0,125.4$, 123.7, 119.1, 109.1, 50.3, 40.2, 35.3, 30.2, 27.9, 25.3, 20.9. LC/ESI-MS: $\mathrm{m} / \mathrm{z}$ value; $469(\mathrm{M}+1)$. Anal calc. for $\mathrm{C}_{23} \mathrm{H}_{24} \mathrm{~N}_{4} \mathrm{O}_{5} \mathrm{~S}(468)$ : C 58.96, H 5.16, N 11.96, O 17.07 Found C 58.92, H 5.19, N 11.86, O 17.13 .

1-[5-(5-Cyclohexyl-[1,3,4]oxadiazol-2-yl)-2-methyl-benzenesulfonyl]-1H-indole (5l). Yield 58\%; m.p. $98{ }^{\circ} \mathrm{C}$. FTIR (KBr) in $\mathrm{cm}^{-1}: 2930,2859\left(\mathrm{CH}_{2}\right.$ str $), 1579(\mathrm{C}=\mathrm{N}), 1471(\mathrm{C}=\mathrm{C}), 1320$ ( $\mathrm{SO}_{2}$ str assym), $1162\left(\mathrm{SO}_{2}\right.$ str sym), $1048(\mathrm{C}-\mathrm{O}-\mathrm{C}) .{ }^{1} \mathrm{H}$ NMR $\left(\mathrm{CDCl}_{3}, 300 \mathrm{MHz}\right) \delta \mathrm{ppm}: 1.38-$ $1.49(\mathrm{~m}, 2 \mathrm{H}), 1.56-1.65(\mathrm{~m}, 2 \mathrm{H}), 1.76-1.86(\mathrm{~m}, 4 \mathrm{H}), 2.06-2.16(\mathrm{~d}, 2 \mathrm{H}), 2.56(\mathrm{~s}, 3 \mathrm{H}), 2.91-3.13$ $(\mathrm{m}, 1 \mathrm{H}), 6.89(\mathrm{~d}, 1 \mathrm{H}, J=7.2 \mathrm{~Hz}), 7.07-7.18(\mathrm{~m}, 3 \mathrm{H}), 7.26(\mathrm{~d}, 1 \mathrm{H}, J=8.0 \mathrm{~Hz}), 7.36(\mathrm{~d}, 1 \mathrm{H}, J=$ $7.6 \mathrm{~Hz}), 7.65(\mathrm{~d}, 1 \mathrm{H}, J=7.8 \mathrm{~Hz}), 8.11(\mathrm{~d}, 1 \mathrm{H}, J=8 \mathrm{~Hz}), 8.49(\mathrm{~s}, 1 \mathrm{H}) .{ }^{13} \mathrm{C}$ NMR $(300 \mathrm{MHz}$, $\left.\mathrm{CDCl}_{3}\right) \delta$ ppm: $168.2,163.8,141.6,139.5,136.5,131.3,130.6,128.7,127.1,124.6,121.8$, 120.3, 119.4, 111.2, 109.5, 102.6, 34.7, 30.2, 27.7, 25.4, 20.2. LC/ESI-MS: m/z value; 422 $(\mathrm{M}+1)$. Anal calc. for $\mathrm{C}_{23} \mathrm{H}_{23} \mathrm{~N}_{3} \mathrm{O}_{3} \mathrm{~S}$ (421): C 65.5, H 5.50, N 9.97, O 11.39. Found C 65.42, H 5.47, N 9.96, O 11.38.

4-[5-(5-Cyclohexyl-[1,3,4]oxadiazol-2-yl)-2-methyl-benzenesulfonyl]-morpholine (5m). Yield $60 \%$; m.p. $98{ }^{\circ} \mathrm{C}$. FTIR $(\mathrm{KBr})$ in $\mathrm{cm}^{-1}: 2925,2855\left(\mathrm{CH}_{2}\right.$ str), $1601(\mathrm{C}=\mathrm{N}), 1457(\mathrm{C}=\mathrm{C}), 1335$ $\left(\mathrm{SO}_{2}\right.$ str assym), $1156\left(\mathrm{SO}_{2}\right.$ str sym $), 1112(\mathrm{C}-\mathrm{O}-\mathrm{C}) .{ }^{1} \mathrm{H}$ NMR $\left(\mathrm{CDCl}_{3}, 300 \mathrm{MHz}\right) \delta \mathrm{ppm:} 1.31-$ $1.45(\mathrm{~m}, 3 \mathrm{H}), 1.62-1.78(\mathrm{~m}, 3 \mathrm{H}), 1.86-1.91(\mathrm{~m}, 2 \mathrm{H}), 2.13-2.18(\mathrm{~m}, 2 \mathrm{H}), 2.71(\mathrm{~s}, 3 \mathrm{H}), 2.96-3.04$ $(\mathrm{m}, 1 \mathrm{H}), 3.20-3.22(\mathrm{q}, 4 \mathrm{H}), 3.75(\mathrm{t}, 4 \mathrm{H}), 7.49(\mathrm{~d}, 1 \mathrm{H}, J=8.1 \mathrm{~Hz}), 7.66-7.72(\mathrm{~m}, 1 \mathrm{H}), 8.18(\mathrm{dd}$, $1 \mathrm{H}, J=7.8 \mathrm{~Hz}), 8.49(\mathrm{~s}, 1 \mathrm{H}) .{ }^{13} \mathrm{C}$ NMR $\left(100 \mathrm{MHz}, \mathrm{CDCl}_{3}\right) \delta \mathrm{ppm}: 170.5,162.8,142.6,136.1$, 133.4, 130.8, 128.3, 122.7, 66.2, 45.3, 35.3, 30.2, 28.9, 25.4, 20.9. LC/ESI-MS: $\mathrm{m} / \mathrm{z}$ value; 392 $(\mathrm{M}+1)$. Anal calc. for $\mathrm{C}_{19} \mathrm{H}_{25} \mathrm{~N}_{3} \mathrm{O}_{4} \mathrm{~S}$ (391): C 58.29, H 6.44, N 10.73, O 16.35 Found C 58.62, H 6.46, N 10.77, O 16.41.

1-Benzhydryl-4-[5-(5-cyclohexyl-[1,3,4] oxadiazol-2-yl)-2-methyl-benzenesulfonyl]-piperazine (5n). Yield 75\%; m.p. $168{ }^{\circ} \mathrm{C}$. FTIR ( $\left.\mathrm{KBr}\right)$ in $\mathrm{cm}^{-1}: 3451$ (NH- str piperazine), 2928, $2853\left(\mathrm{CH}_{2}\right.$ str), $1557(\mathrm{C}=\mathrm{N}), 1449(\mathrm{C}=\mathrm{C}), 1326\left(\mathrm{SO}_{2}\right.$ str assym $), 1156\left(\mathrm{SO}_{2}\right.$ str sym $), 1080(\mathrm{C}-\mathrm{O}-\mathrm{C}) .{ }^{1} \mathrm{H}$ NMR $\left(\mathrm{CDCl}_{3}, 300 \mathrm{MHz}\right) \delta$ ppm: 1.37-1.46 (m, 2H) 1.80-1.91 (m, 3H), 2.05-2.16 (d, 2H), 2.45$2.48(\mathrm{t}, 4 \mathrm{H}), 2.70(\mathrm{~m}, 3 \mathrm{H}), 2.95-3.03(\mathrm{~m}, 1 \mathrm{H}) 3.18-3.24(\mathrm{~m}, 4 \mathrm{H}), 4.23(\mathrm{~s}, 1 \mathrm{H}), 7.15-7.19(\mathrm{~m}, 2 \mathrm{H})$, $7.21-7.31(\mathrm{~m}, 4 \mathrm{H}), 7.35(\mathrm{dd}, 4 \mathrm{H}, J=12.9 \mathrm{~Hz}), 7.47(\mathrm{~d}, 1 \mathrm{H}, J=7.8 \mathrm{~Hz}), 8.17(\mathrm{~d}, 1 \mathrm{H}, J=7.8$ $\mathrm{Hz}), 8.59(\mathrm{~s}, 1 \mathrm{H}) .{ }^{13} \mathrm{C} \mathrm{NMR}\left(100 \mathrm{MHz}, \mathrm{CDCl}_{3}\right) \delta \mathrm{ppm}: 170.3,163.0,142.3,141.6,133.9,131.1$, 130.0, 127.8, 125.3, 123.8, 122.6, 114.6, 65.8, 50, 35.3, 30.1, 27.9, 25.4, 20.9, 15.3. LC/ESIMS: $\mathrm{m} / \mathrm{z}$ value; $557(\mathrm{M}+1)$. Anal calc. for $\mathrm{C}_{19} \mathrm{H}_{25} \mathrm{~N}_{3} \mathrm{O}_{4} \mathrm{~S}$ (556): C 69.04, H 6.52, N 10.06, O 8.62 Found C 69.02, H 6.66, N 9.96, O 8.39. 


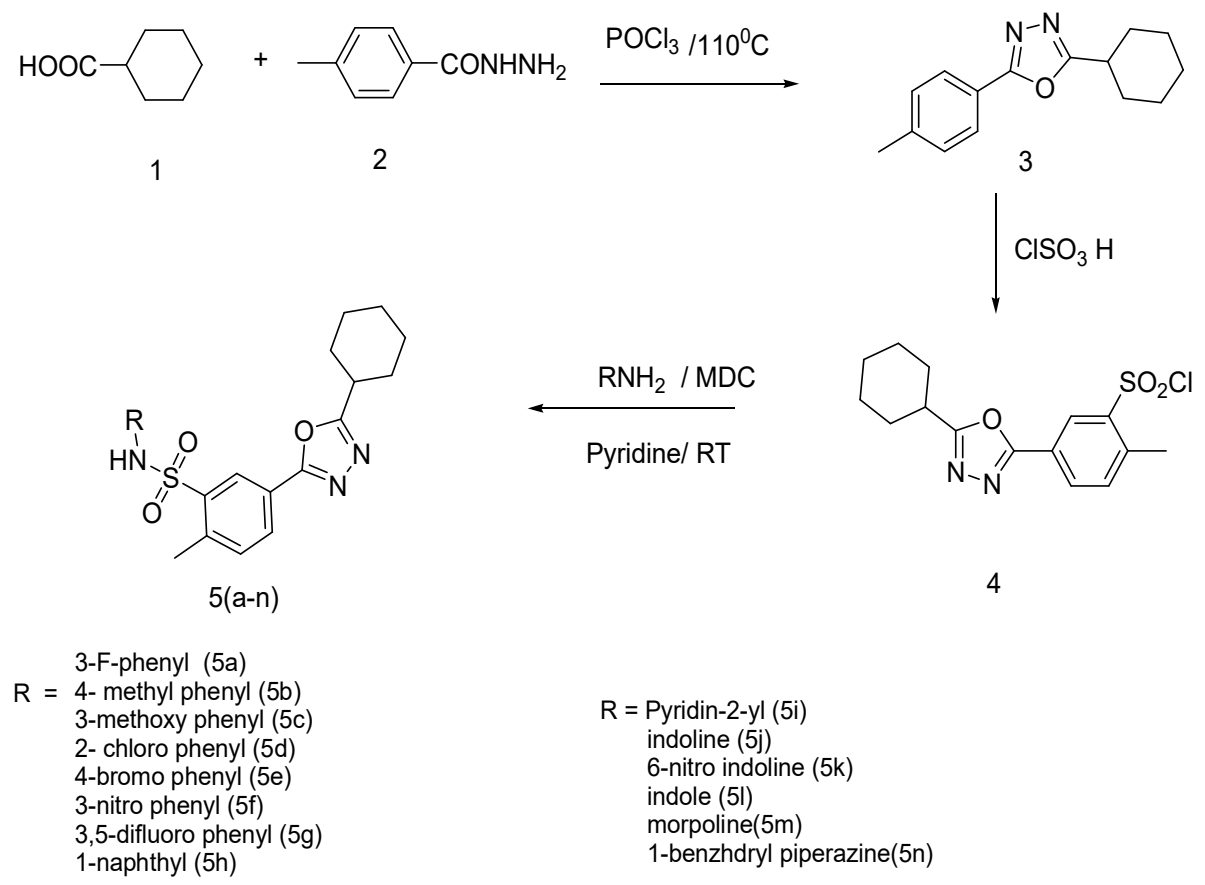

Figure 1. Scheme route of 2,5-disubstituted-1,3,4-oxadiazole derivatives.

Antibacterial assay

The newly synthesized compounds were screened for their in vitro antibacterial activity against pathogens gram positive: E. coli, S. Aureus; gram negative: P. aeruginosa and B. subtilis at various concentrations at $100 \mu \mathrm{g} / \mathrm{mL}$ by using disc diffusion method [33-34]. All the test compounds were dissolved in DMSO and cultured in Mueller-Hinton broth (MHB). $6 \mathrm{~mm}$ diameters of sterile discs were placed in the petri plates, to which appropriate concentrations of different synthesized compounds were added. The three triplicates were maintained for each plate and were incubated at $37{ }^{\circ} \mathrm{C}$ for $24 \mathrm{~h}$. Amikacin $(30 \mu \mathrm{g})$ was used as a positive reference standard and DMSO as negative control. The diameter of the clear zone around the disc was measured and expressed in millimeters as its zone of inhibition.

\section{Antifungal assay}

The antifungal activities of synthetic compounds were evaluated by disc diffusion technique. All the compounds are screened in vitro for their antifungal activity against Candida albicans and Aspergillus niger. Potato dextrose agar (PDA) was used for fungal cultures. The culture medium was inoculated with the fungal strains separately suspended in Potato dextrose broth. The synthesized compounds were applied on the sterile disc. Standard antibiotic (ketoconazole 30 $\mu \mathrm{g}$ ) was used as positive control, and fungal plates were incubated at $37{ }^{\circ} \mathrm{C}$ for $72 \mathrm{~h}$ and triplicates were maintained. The diameters of zone of inhibition observed were measured.

\section{In vitro anti-inflammatory activity (BSA assay)}

The synthesized compounds were screened for their in vitro anti-inflammatory activity by using albumin denaturation assay by following the procedure reported by Kavitha et al. [35]. 
In vitro anti-diabetic activity ( $\alpha$-amylase assay)

All the synthesized compounds were evaluated for in vitro anti-diabetic activity by $\alpha$-amylase assay by following procedure reported by Kavitha et al. [35].

\section{Theoretical calculations}

Quantum chemical parameter like dipole moment, $E_{\mathrm{HOMO}}, E_{\mathrm{LUMO}}$ and energy gap $(\Delta \mathrm{E})$, global hardness $(\eta)$, global softness $(S)$, chemical potential $(\mu)$, electrophilic index $(\omega)$ of the all title compounds were fully optimized using density functional theory method by RB3LYP. The structure of the all titled compounds were geometrically optimized by functional hybrid RB3LYP with electron basis set 6-311++G(2d,p) for the atoms with Gaussian 09 [36]. C $\log \mathrm{P}$ was calculated by Chem draw ultra 8.0.

\section{RESULTS AND DISCUSSION}

\section{Chemistry}

All synthesized compounds are confirmed by absorption bands $3080-3150 \mathrm{~cm}^{-1}$ corresponding to NH stretching of the amide. The absorption peaks are observed at $2927-2940 \mathrm{~cm}^{-1}$ and $2850-$ $2862 \mathrm{~cm}^{-1}$ due to aliphatic $\mathrm{CH}_{2}$ stretching. FT-IR stretching vibrations appeared at 1327-1339 ( $\mathrm{SO}_{2}$ asymmetric) and $1150-1162 \mathrm{~cm}^{-1}\left(\mathrm{SO}_{2}\right.$ symmetric) for all synthesized compound. IR stretching bands showed around at $1576 \mathrm{~cm}^{-1}(\mathrm{C}=\mathrm{N})$ and $1584 \mathrm{~cm}^{-1}(\mathrm{C}=\mathrm{C})$. The stretching vibrations are appeared around at $1081 \mathrm{~cm}^{-1}(\mathrm{C}-\mathrm{O}-\mathrm{C})$ which are present in 1,3,4-oxadiazole ring, respectively.

For NMR spectra, a singlet peak was observed at 2.63-2.78 ppm due to the presence of $\mathrm{CH}_{3}$ group and also singlet peak appeared at $3.73 \mathrm{ppm}$ for $\mathrm{OCH}_{3}$. The appearance of multiplet at 2.91-3.10 ppm indicated that the presence of $\mathrm{CH}$ (aliphatic) of the synthesized compounds. A doublet or multiplet peaks were observed at $6.32-8.12 \mathrm{ppm}$ due to the presence of aromatic and heterocyclic protons. The ${ }^{1} \mathrm{H}$ NMR spectra of the sulphonamide derivatives showed most downfield singlet signal at 8.32-9.93 ppm for sulphonamide $\mathrm{NH}$ proton. ${ }^{13} \mathrm{C}$ NMR spectrum of compound 3 was clearly confirmed by the chemical shift at $\delta 168.5$ and $\delta 163.2 \mathrm{ppm}$. The characteristic peaks for aromatic $(\mathrm{C}-\mathrm{H})$ at around $\delta 132 \mathrm{ppm}$. The structures of all synthesized compounds were confirmed by FT-IR, NMR Mass and elemental analysis.

\section{Antibacterial studies}

All the titled compounds were subjected to antibacterial activity against gram positive bacteria and gram negative bacteria at concentration of $100 \mu \mathrm{g} / \mathrm{mL}$ by using disc diffusion technique. Amikacin was used as reference drug. The zone of inhibition of the synthesized compounds is summarized Table 1. From obtained data, all synthesized compounds exhibited moderate to better activity against all the concentrations of $100 \mu \mathrm{g} / \mathrm{mL}$. Compounds $\mathbf{5 a}, \mathbf{5 b}, \mathbf{5 c}, \mathbf{5 d}, \mathbf{5 f}$, and $5 \mathrm{~g}$ exhibited good activity against $B$. subtilis and E. coli compared with the standard. Furthermore, synthetic compounds $\mathbf{5 a}, \mathbf{5 f}$, and $\mathbf{5 g}$ were found to be effective against $P$. aeruginosa. For these, compounds were optimized by DFT studies. Compound $\mathbf{5 i}$ was inactive against most of the bacterial strains.

\section{Antifungal studies}

All synthesized compounds were evaluated for their antifungal activity against Candida albicans and Aspergillus nigar at $100 \mu \mathrm{g} / \mathrm{mL}$ with Ketaconazole as standard drug. Compounds 5a and 5n displayed good activity against the fungai $C$. albicans. In the novel series, the 
majority of the synthesized compounds exhibited moderate to good activity against $C$. albicans with the zone of inhibition $9-13 \mathrm{~mm}$. In the case of $A$. niger, the most of the synthesized compounds displayed moderate activity against all tested organisms with the zone of inhibition $8-10 \mathrm{~mm}$.

Table 1. Zone of inhibition of antimicrobial activities of all synthesized compounds (5a-5n).

\begin{tabular}{|c|c|c|c|c|c|c|}
\hline \multirow{3}{*}{ Compound code } & \multicolumn{6}{|c|}{ Diameter of zone of inhibition in $\mathrm{mm}$} \\
\hline & \multicolumn{2}{|c|}{ Gram positive bacteria } & \multicolumn{2}{|c|}{ Gram positive bacteria } & \multicolumn{2}{|c|}{ Antifungal } \\
\hline & SA & $\mathrm{BS}$ & $\mathrm{EC}$ & PA & CA & AN \\
\hline $5 \mathbf{5 a}$ & 18 & 17 & 15 & 24 & 13 & - \\
\hline $5 b$ & 10 & 13 & 13 & 11 & 10 & 8 \\
\hline $5 c$ & 10 & 12 & 12 & 10 & 11 & 10 \\
\hline 5d & 11 & 13 & 13 & 11 & 10 & 8 \\
\hline $5 e$ & 11 & 13 & 12 & 11 & 10 & 8 \\
\hline $5 f$ & 13 & 14 & 14 & 20 & 10 & 8 \\
\hline $5 g$ & 15 & 14 & 16 & 26 & 10 & 8 \\
\hline $5 \mathrm{~h}$ & 8 & 8 & 9 & 10 & - & 7 \\
\hline $5 i$ & - & - & - & 9 & - & 8 \\
\hline $5 \mathbf{j}$ & 10 & 12 & 10 & 8 & 10 & 8 \\
\hline $5 \mathrm{k}$ & 10 & 10 & 10 & - & 9 & 8 \\
\hline 51 & 10 & 12 & 10 & 10 & 10 & 8 \\
\hline $5 \mathrm{~m}$ & 11 & 12 & 8 & 12 & 13 & 9 \\
\hline 5n & 10 & 12 & 10 & 10 & 10 & 8 \\
\hline Amikacin & 29 & 28 & 26 & 25 & & \\
\hline Ketaconazole & & & & & 20 & 22 \\
\hline
\end{tabular}

$\mathrm{SA}=$ Staphylococcus aureus ATCC 9144, BS = Bacillus subtilis ATCC 6051, EA $=$ Escherichia coli ATCC 25922, PA= Pseudomonas aeruginosa ATCC-2853, CA=Candida albicans $\mathrm{MTCC}-227, \quad \mathrm{AN}=$ Aspergillus niger MTCC-281.

The results indicated that the presence of halogen, nitro substituted benzene sulfonamide with 1,3,4-oxadiazole moiety showed significant antimicrobial activity. (i) It was observed that fluoro substituted 1,3,4-oxadiazole derivatives were more active compared to chloro and bromo derivatives, followed by derivatives like methoxy, methyl groups respectively [37]. (ii) The presence of electron withdrawing groups and electron donating groups in phenyl ring may enhance antimicrobial activity of the titled compounds [38]. (iii) Hetero aryl ring (like indole) substituted with 1,3,4-oxdiazole moiety enhances the anti-diabetic activity. (iv) Results revealed that, most of the tested compounds showed good anti-inflammatory activities, due to the presence of hereto substituted aryl ring in the 1,3,4-oxdaizole derivatives.

In vitro anti-inflammatory activity

All the synthesized compounds (5a-n) were evaluated for their in vitro anti-inflammatory activity and were carried out using serum albumin denaturation technique with five different concentrations such as 50,100, 200, 400 and $500 \mu \mathrm{g}$, respectively. In the series, most of the compounds $\mathbf{5 b}, \mathbf{5 e}, \mathbf{5 f}$ and $\mathbf{5 l}$ exhibited good activity with $\mathrm{IC}_{50}$ values of $118.2,110.9,140.3$, and $140.9 \mu \mathrm{M}$. While, synthesized compounds $\mathbf{5 c}$ and $\mathbf{5 d}$ are more active than drug diclofenac $\left(\mathrm{IC}_{50}\right.$ $=156 \mu \mathrm{M})$. Compound $\mathbf{5 n}$ showed less activity than all other compounds. The resulting data of the anti-inflammatory activity of all the synthesized compounds are shown in Figure 2. 


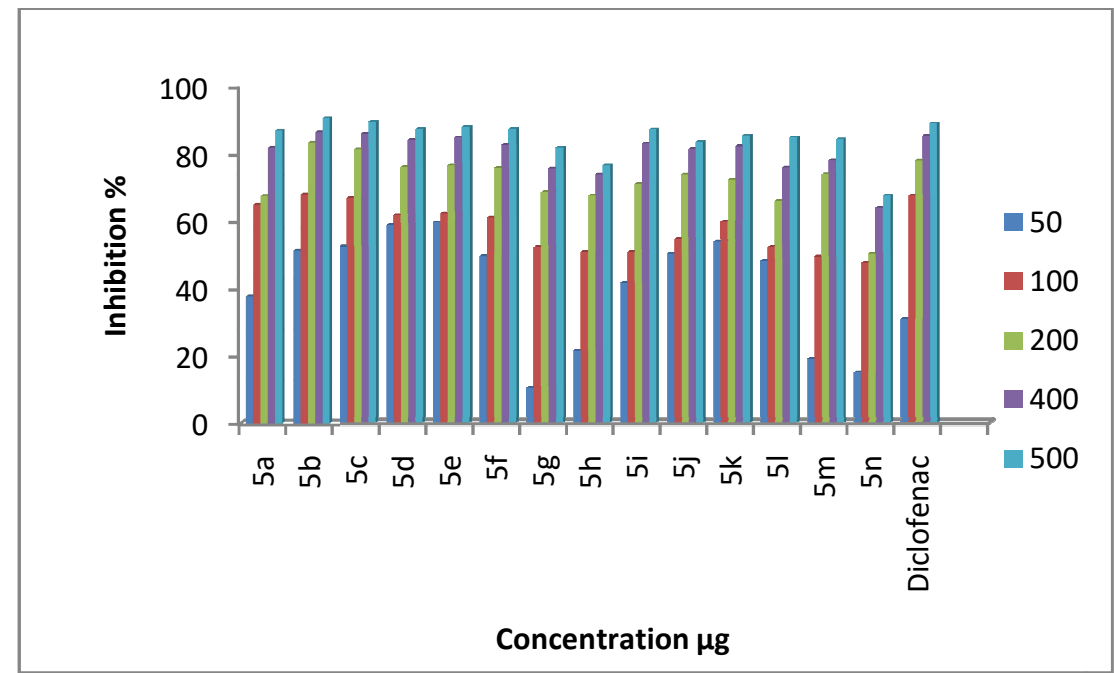

Figure 2. Anti- inflammatory activities of tested compounds (5a-5n).

In vitro antidiabetic activity

In this present study, all synthesized compounds were screened against $\alpha$-amylase activity. Synthesized compounds were checked with five different concentrations 50, 100, 250, 500, and $1000 \mu \mathrm{m}$. The compounds $\mathbf{5 j}, \mathbf{5 k}, \mathbf{5}$ l and $\mathbf{5 n}$ displayed stronger inhibitory activity with $\mathrm{IC}_{50}$ values of $(6.23,6.59,2.34$ and 7.15$) \mu \mathrm{M}$ than standard drug acarbose $\left(\mathrm{IC}_{50}=2.53 \mu \mathrm{M}\right)$. Furthermore, the remaining compounds have shown moderate to weak activities $\left(\mathrm{IC}_{50} \geq 100\right.$ $\mu \mathrm{M})$. The resulting bar graph representation of anti-diabetic activities of title compounds is shown in Figure 3.

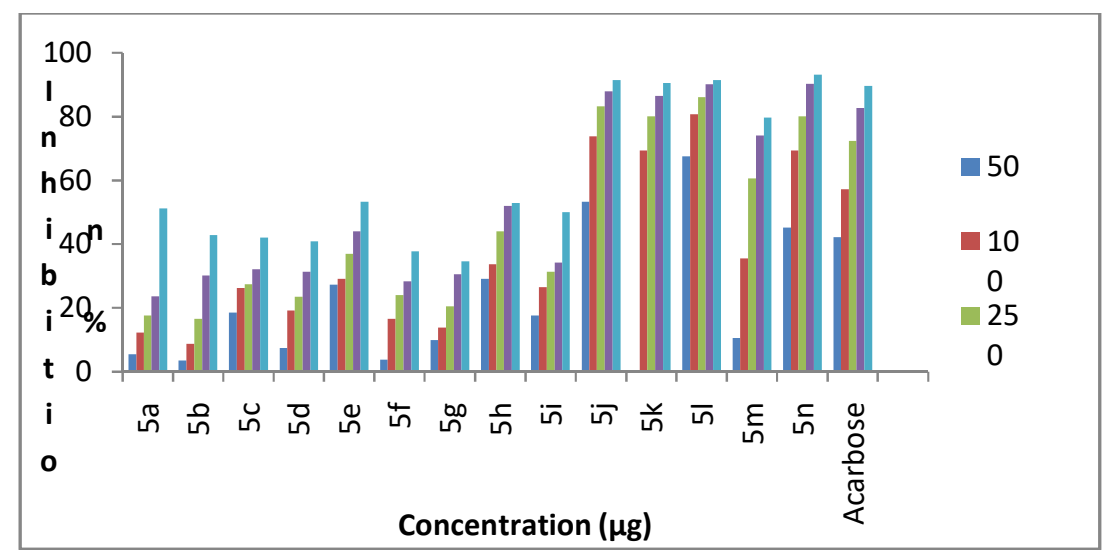

Figure 3. Antidiabetic activities of tested compounds (5a-5n). 


\section{Theoretical calculations}

Quantum chemical parameters such as HOMO, LUMO, energy gap $(\Delta \mathrm{E})$, global hardness, and electrophilicity index are calculated and shown in Table 2. HOMO and LUMO orbital are important orbital in the molecule because that involving chemical reaction [39-41].

Table 2. Quantum chemical descriptor for synthesized compounds (5a-5n) calculated using RB3LYP/6$311 \mathrm{G}(\mathrm{d}, \mathrm{p})$ and values in a.u.

\begin{tabular}{|c|c|c|c|c|c|c|c|c|c|}
\hline Compound & $E_{\text {ном⿰ }}$ & $E_{\text {LUMO }}$ & $\Delta \mathrm{E}$ & $\mu$ & $\mu(\mathrm{D})$ & $\eta$ & $\mathrm{S}$ & $\omega$ & $\mathrm{C} \log \mathrm{P}$ \\
\hline $\mathbf{5 a}$ & -0.19027 & -0.1662 & -0.02407 & -0.17823 & 7.2166 & 0.01203 & 41.54 & 1.3200 & 4.364 \\
\hline $\mathbf{5 b}$ & -0.20236 & -0.15489 & -0.04747 & -0.17862 & 3.4698 & 0.02373 & 21.06 & 0.6721 & 4.696 \\
\hline $\mathbf{5 c}$ & -0.20922 & -0.15868 & -0.05054 & -0.18375 & 3.6699 & 0.02527 & 19.78 & 0.6608 & 4.131 \\
\hline $\mathbf{5 d}$ & -0.17862 & -0.12222 & -0.05648 & -0.15042 & 3.5890 & 0.02824 & 17.70 & 0.4006 & 4.934 \\
\hline $\mathbf{5 e}$ & -0.17953 & -0.12358 & -0.05595 & -0.15156 & 4.0261 & 0.02798 & 17.87 & 0.4105 & 5.084 \\
\hline $\mathbf{5 f}$ & -0.18021 & -0.07526 & -0.10495 & -0.12773 & 7.8339 & 0.05247 & 9.528 & 0.15545 & 4.171 \\
\hline $\mathbf{5 g}$ & -0.18804 & -0.08381 & -0.10423 & -0.13592 & 5.643 & 0.05211 & 9.594 & 0.17721 & 4.516 \\
\hline $\mathbf{5 h}$ & -0.21128 & -0.14594 & -0.06534 & -0.17861 & 4.6412 & 0.03267 & 15.30 & 0.48823 & 5.371 \\
\hline $\mathbf{5 i}$ & -0.22455 & -0.14562 & -0.07894 & -0.18508 & 5.0767 & 0.03947 & 12.66 & 0.43395 & 3.141 \\
\hline $\mathbf{5 j}$ & -0.22943 & -0.06082 & -0.16861 & -0.14512 & 6.3294 & 0.08305 & 5.93 & 0.12490 & 4.393 \\
\hline $\mathbf{5 k}$ & -0.14443 & -0.06118 & -0.0832 & -0.10280 & 6.456 & 0.04160 & 12.01 & 0.12702 & 4.502 \\
\hline $\mathbf{5} \mathbf{5}$ & -0.14171 & -0.05664 & -0.0857 & -0.09917 & 6.3939 & 0.04285 & 11.66 & 0.11475 & 4.969 \\
\hline $\mathbf{5 m}$ & -0.1259 & -0.07874 & -0.04716 & -0.10232 & 2.3943 & 0.02358 & 21.20 & 0.22199 & 2.625 \\
\hline $\mathbf{5 n}$ & -0.18287 & -0.05918 & -0.12369 & -0.12102 & 6.4525 & 0.06185 & 8.084 & 0.11840 & 6.256 \\
\hline
\end{tabular}

Compound 5a has the highest LUMO and HOMO energy gap and compound $\mathbf{5 j}$ has lowest value among all the synthesized compounds. The HOMO-LUMO energy gap increases with increases chemical reactivity of the molecules and also increases in activity against all the tested microorganisms. The global hardness $(\eta)$ is one of the properties of the molecule use to measure the intensity of chemical reactivity. The decreasing order lower values of $\eta$ for these compounds are $\mathbf{5 c}>\mathbf{5 b}>\mathbf{5 m}>\mathbf{5 a}$. The lowest chemical hardness for the compound has less stable and more reactive. Global softness $(\mathrm{S})$ is the reciprocal of the hardness and is related to chemical reactivity and energy gap of the molecules. Therefore, compound 5a is more reactive than others synthesized compounds. Electrophilic index $\left(\omega=\mu^{2} / 2 \eta\right)$ is calculated by chemical potential and chemical hardness. It is used to measure the propensity or capacity of the species to accept the electrons. The results of electrophilic index indicate that compound $\mathbf{5 l}$ acts as a strongest nucleophile and $\mathbf{5 a}$ acts as a strongest an electrophile.

Lipophilicity, chemical reactivity, energy gap have significant properties on bioactive of the compounds. In general, the chemically reactive compounds are less suitable for the biological activity. Apart from this, synthesized compounds have the lower values of $\mathrm{C} \log \mathrm{P}$ showed good antimicrobial activities. It was explained by well-known lipophlic compounds are favorable for being delivered binding site to the organism. Compound $\mathbf{5 m}$ has lower value (2.325) than all other synthesized compounds and were calculated using Chem Draw software 8.0. It could be concluded that halogen, $\mathrm{OCH}_{3}$ and $\mathrm{CH}_{3}$ substituted phenyl group which increase the stability of the compound. This is confirmed by DFT studies which give better microbial activity with their derivatives. 


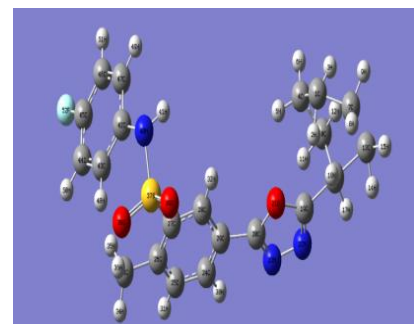

Optimized structure

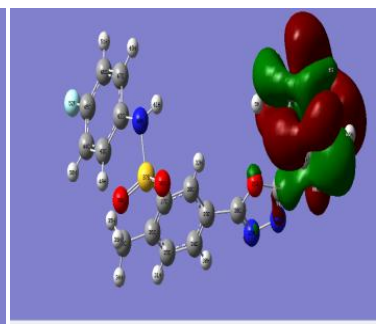

HOMO

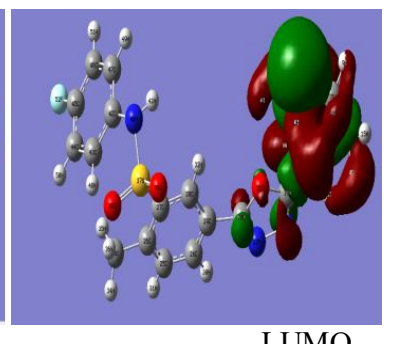

LUMO

Figure 4. Frontier orbitals of synthesisd compound $\mathbf{5 a}$.

\section{CONCLUSION}

In this study, we have synthesized a novel series of 1,3,4-oxadaizole and evaluated for their in vitro antimicrobial activity, anti-inflammatory, antidiabetic activities. The in vitro antimicrobial activity of these tested compounds showed moderate to good activity. Compound 51 is more active than standard acarbose. Results showed that the majority of the synthesized compounds exhibited excellent anti-inflammatory activity and it further considered for vivo assays for finding leading anti-inflammatory agents. All the synthesized compounds were optimized by density functional theory (DFT) studies indicated that zone of the inhibition of compounds (experimental) which is correlated with quantum parameters (theoretically) and gave useful information about chemical reactivity and stability of the molecules.

\section{REFERENCES}

1. Hijira, R.; Abdul, Q.; Zulfiqar, A.; Shahid, N.; Asmat, Z.; Tanzeela Q.S. Synthesis and characterization of novel sulfonamides derivatives and their antimicrobial, antioxidant and cytotoxicity evaluation. Bull. Chem. Soc. Ethiop.2017, 31, 491-498.

2. Nadia, S.; El-Sayed.; Eman, R.E.; Saadia, M.; Mohammed, M.; El-Kerdawy. Synthesis and antitumor activity of new sulfonamide derivatives of thiadiazolo(3,2-a) pyrimidines. Eur. $J$. Med. Chem. 2011, 46, 3714-3720.

3. Radhika, S.; Subhangi, S.S. Design and synthesis of sulfonamide derivatives of pyrrolidine and piperidine as antidiabetic agents. Eur. J. Med. Chem. 2014, 90, 342-350.

4. Jose, N.D.; Caritza, L. Synthesis and antimalarial activity of sulfonamide chalcone derivatives. II Farmoco 2005, 60, 307-311.

5. Neslihan, O.; Hikmet, K.; Nurcan, K.; Tulay, B. Synthesis, characterization and antimicrobial activity of new aliphatic sulfonamide. Bioorg. Med. Chem. 2007, 15, 51055109.

6. Ahmed, K.; Swapna, P.; Rajesh, N.R.; Soma, G. Synthesis biological evaluation of new oxazolidino-sulfonamides as potential antimicrobial agents. Eur. J. Med. Chem. 2013, 62, 661-669.

7. Rathish, I.G.; Kalim, J.; Shamim, A.; Sameena, B.; Alam, M.S.; Pillai, K.K.; Surender S.; Vivek, B. Synthesis and anti-inflammatory activity of some new 1,3,5-trisubstituted pyrazolines bearing benzene. Bioorg. Med. Chem. Lett. 2009, 19, 255-258.

8. Mina, S.; Fereshteh, G.; Mohammed, M.; Gholamreza, D.; Mohammad, A.F.; Alireza F.; Abbas, S. Synthesis and biological investigation of some novel sulfonamide and amide derivatives. Iran. J. Pharm. Res. 2014, 13, 881-892.

9. Zhong, C.; Zhong-chang, W.; Zhe, L.; Peng-Fei, W.; Han-Yue, Q.; Long-Wang, C.; XiaoYuan, L.; Peng-Cheng, L.; Hai-Liang, Z. Design, synthesis biological evaluation and 
molecular modeling of dihydropyrazole sulfonamide derivatives $\mathrm{CO}-\mathrm{X} / \mathrm{COX}-2$ inhibitors. Bioorg. Med. Chem. Lett. 2015, 25, 1947-1951.

10. Ghulam, M.; Islam, U.K.; Muhammad, A.; Iftikhar, A.; Sohali, A.S.; Muhammad, S. Synthesis of new sulfonamide as lipoxygenase inhibitors. Bioorg. Med. Chem. 2012, 20 , 2535-2539.

11. Seema, B.; Rekha, T.; Abha, S.; Hyejin, C.; Hana, R.; Weihong, Z.; Harry, L.; Bela, T.; Marianna, T. Sulfonamides as multifunctional agents for Alzhimers disease. Bioorg. Med. Chem. Lett. 2015, 25, 626-630.

12. Mohammed, J.A.; Vikram, P.S.; Ramdayal, S.; Surender, S.J.; Sabina,Y.; Pradeep, K. Synthesis, anticancer, and molecular docking studies of 2-(4-cholorophenyl)-5-aryl-1,3,4oxadiazole analogues. Med. Chem. Res. 2013, 3, 294-297.

13. Murthy, M.S.R.; Ramalingeswara, R.B.; Maohana, R.K.; Lekshmi, N.R.; Ruby, J.A. Synthesis of piperazinyl benzothiazole/benzoxazole derivatives coupled with 1,3,4oxadiazole-2-thiol: Novel hybrid heterocycles as anticancer agents. Med. Chem. Res. 2013, 22, 4980-4991.

14. Bereket, M.; Xin, Q.; Suresh, E.; Donald, S.; Neelly, M.K.; Soliman, F. Design and evaluation of novel oxadiazole derivatives as potential prostate cancer inhibitors. Bioorg. Med. Chem. Lett. 2016, 26, 2847-2851.

15. Rajesh, A.R.; Shweta, G.D.; Niteshkumar, S. Synthesis and evaluation of novel 1,3,4oxadiazole derivatives of marine bromopyrrole alkaloids as antimicrobial agent. Bioorg. Med. Chem. Lett. 2012, 22, 6429-6432.

16. Desai, N.C.; Amit, D.M.; Kiran, R.M.; Yogesh, R.M. Synthesis and antimicrobial screening of 1,3,4-oxadiazole and clubbed thiopene derivatives. J. Saudi Chem. Soc. 2014, 18, 255261.

17. Shrihar, M.; Arun, I.M.; Peethambar, S.K.; Hoong, K.F. Synthesis and biological evaluation of newer analogues of 2,5-disubstituted 1,3,4-oxadiazole containing pyrazole moiety as antimicrobial agents. Arabian J. Chem. 2014, 7, 1185-1191.

18. Desai, N.C.; Kotadiya, G.M.; Triveni, A.R.; Khedkar, V.M. Synthesis, biological evaluation and QSAR studies of novel pyrazole bearing pyridyl oxadiazole analogues as potential antimicrobial agents. Med. Chem. Res. 2016, 25, 712-727.

19. Hajimahdi, Z.; Zarghi, A.; Zabihollahi, R.; Aghasadeghi, M.R. Synthesis, biological evaluation and molecular modeling studies of new 1,3,4-oxadiazole and 1,3,4-thiadiazolesubstituted 4-oxo-4H-pyrido[1,2-a] pyrimidines as anti HIV agents. Med. Chem. Res. 2013, $22,2467-2475$

20. Wenneng, W.; Qin, C.; Anqi, T.; Guangqi, J.; Guiping, O. Synthesis and antiviral activity of 2-substituted-methylthio-5-(4-amino-2-methylpyrimidin-5-yl)-1,3,4-oxadiazole derivatives. Med. Chem. Lett. 2015, 25, 2243-2246.

21. Harish, K.; Sadique, J.A.; Suroor K.A.; Mohammad, A. 1,3,4-Oxadiazole/thiadiazole and 1,2,4-triazole derivatives of biphenyl-4-yloxy acetic acid:Synthesis and preliminary evaluation of biological properties. Eur. J. Med. Chem. 2008, 43, 2688-2698.

22. Sadaf, G.J.; Suroor, K.A.; Nadeem, S. Synthesis and pharmacological evaluation of condensed heterocyclic 6-substitued 1,2,4-triazolo-[3,4-b]-1,3,4-thiadiazole and 1,3,4oxadaizole derivatives of isoniazid. Bioorg. Med. Chem. Lett. 2010, 20, 4762-4765.

23. Hemalatha, G.; Sarangapani, M. Synthesis and screening of some novel substituted indole contained 1,3,4-oxadiazole and 1,2,4-triazole moiety. Chin. Chem. Lett. 2013, 24, 127-130.

24. Kikkeri, P.; Harish.; Kikeri M.N.; Lingappa, M.; Basayapatna, P.N. Synthesis of novel 1-[5(4-methoxy-phenyl)-[1,3,4] oxadizol-2-yl]-piperazine derivatives and evaluation of their in vivo anticonvulsant activity. Eur. J. Med. Chem. 2013, 65, 276-283.

25. Muthupandian, S.; Sisirkumar, B.; Davoodbasha, M.; Periyakaruppan P.; Arivalagan, P. Synthesis of silver nanoparticles from Bacillus brevis (NCIM 2533) and their antibacterial activity against bacteria. Microb. Pathog. 2018, 116, 221-226. 
26. Muthupandi, K.; Prakash, P.; Saravanan, M.; Mahalakshmi Mohan. Antibacterial efficacy of silver nanoparticles against multi-drug resistant clinical from post-surgical wound infections. Microb. Pathog. 2018. DOI: 10.1016/jmicpath. 2017.04.013.

27. Muthupandian, S.; Selvaraj, A.; Thangavelu, L.; Arivalagan, P. Synthesis of silver nanoparticles from phenerochaete chrysosporium (MTCC-787) and their antibacterial activity against human pathogenic bacteria. Microb. Pathog. 2018, 117, 68-72.

28. Ramasamy, S.; Muthupandian, S.; AndavarRaja, P.; Konathala, R.S.; Masilamani, S.; Muhammad, O.; Ramachandran, B.; Hamed, B. Biomimetic synthesis of silver nanoparticles from Streptomyces atrovirens and their potential anticancer activity against human breast cancer lines. IET Nanobiotechnol. 2016. DOI: 10.1049/iet-nbt.2016.0222.

29. Hamed, B.; Muhammad, O.; Zabtakhan, S.; Muthupandiya, S. Anticancer green bionanomaterials: Present status and future prospects. Green. Chem. Lett. Rev. 2017, 10, 285-314.

30. Muhammad, O.; Ali, T.K.; Abida, R.; Nazar, U.I.; Muhammad, A.; Muthupandiyan, S.; Muhammad, A.; Irshad, A.; Muhammad, S.; Zabta Khan, S. Multifuntional theranostic applications of biocompatible green synthesised collidal nnoparticles. Appl. Microbiol. Biotechnol.2018. DOI: 10.007/s00253-018-8928-2.

31. Muthupandiyan, S.; Tsehaye, A.; Atsebaha, G.; Dawit, G.; Tadele, A.; Haftamu, H.; Hamed, B.; Kumaresan, R. Nano-medicine as a newly emerging approach to combat human immunodeficiency virus (HIV). Pharm. Nanotechnol. 2018, 6, 17-27.

32. Raghunath, T.B.; Ravindra, J. Synthesis, chacterization and antimicrobial evaluation of novel urea, sulphonamide, acetamide 3,4-dihydropyrazino[1,2-a]indol-1(2H)-one dereivatives. Arab. J. Chem. 2015. DOI: 10.1016/j.arabjc.2015.08.03.

33. Bauer, A.W.; Kirby, W.M.; Sherris, J.C.; Turck, M.M. Antibiotic susceptibility testing by a standardized single disk method. Am. J. Clin. Pathol. 1966, 45, 493-496.

34. Zeba, S.N.; Farheen, F.; Mohammed, M.T.N.; Anis, A.A.U. Synthesis, characterization and antimicrobial evaluation of novel halopyrazole derivatives. J. Saudi. Chem. Soc. 2013, 17, 237-243.

35. Kavitha, S.; Kannan, K.; Gnanavel, S. Synthesis, chacterization and biological evaluation of novel 2,5substituted-1,3,4-oxadiazole derivatives. Saudi Pharm. J. 2017, 25, 337-345.

36. Zulfareen, N.; Kannan, K.; Venugopal, T.; Gnanavel, S. Synthesis, chacterization and corrosion inhibition efficieny of N-(4-(morpholinomethyl carbamoyl phenyl) furan-2carboxamide for brass in $\mathrm{HCl}$ medium. Arabian J. Chem. 2016, 9, 121-135.

37. Juan, M.; Sanchez-Calvo, G.B.R.; Guillermo, G.V.; Alexandra, G.; Duran, M.M.; Manuel, R.A.; Jose, M.M.G.; Francisco, A.M. Synthesis, antibacterial and antifungal activities of naphthoquinone derivatives: A structure-activity relationship study. Med. Chem. Res. 2016, $25,1274-1285$.

38. Mahesh, K.; Balasubramanian, N.; Pradeep, K.; Kalavathy, R.; Vasudevan, M.; Rahesh Kumar, M.; Abu Bakar, A.M. 4-(1-Aryl-5-chloro-2-oxao-1,2-dihydro-indol-3ylideneamino)-N-substituted benzene sulfonamides: Synthesis, antimicrobial, anticancer, evaluation and QSAR studies. Arabian J. Chem. 2014, 7, 396-447.

39. Wahida, B.; Nathalie, D.; Malika, B.; Kamel, B.; Imene, B.; Hajira, B.; Nour-Eddine Aouf. Synthesis and antibacterial activity of sulphonamides: SAR and DFT studies. J. Mol. Struc. 2014, 1074, 180-185.

40. Selma, S-H.; Mirsada, S.; Hurija; Dzudzevic-Cancar.; Snezana, T.; Suncica; Dzenita, Softics.; Davorka, Z. DFT study and microbiology of coumarin-based compounds containing a chalcone moiety. J. Serb. Chem. Soc. 2014, 79, 435-443. 41. Murugavel, S.; Manikandan, N.; Lakshmanan, D.; Kanagaraj, N.; Paramasivan, T.P. Synthesis, crystal, DFT and antibacterial activity studies of (E)-2-benzyl-3-(furan-3-yl)-6,7-dimethoxy-4-(2-phenyl1H-inden-1,2,3,4-tetrahydro-isoquinoline. J. Chil. Chem. Soc, 2015, 60, 3015-3020. 